\title{
Clinical study of the correlation between complement factor $H$ polymorphism and age-related macular degeneration
}

\author{
H.T. Dong*, J.X. Zhang*, Q.M. Li and F.Z. Li \\ Department of Ophthalmology, First Affiliated Hospital of Zhengzhou University, \\ Zhengzhou, China \\ *These authors contributed equally to this study. \\ Corresponding author: Q.M. Li \\ E-mail: donghongtao211@163.com
}

Genet. Mol. Res. 15 (3): gmr.15038457

Received March 7, 2016

Accepted July 26, 2016

Published September 16, 2016

DOI http://dx.doi.org/10.4238/gmr.15038457

Copyright (C) 2016 The Authors. This is an open-access article distributed under the terms of the Creative Commons Attribution ShareAlike (CC BY-SA) 4.0 License

\begin{abstract}
This study aimed to investigate the correlation between age-related macular degeneration (AMD) of the liver-kidney yindeficiency type and complement factor $\mathrm{H}(\mathrm{CFH})$ polymorphism, and to determine whether the $\mathrm{C}$ allele of the $\mathrm{T} 1277 \mathrm{C}(\mathrm{Y} 402 \mathrm{H})$ variant is a risk factor for this condition. We performed a case-control investigation of 60 patients with liver-kidney yin-deficiency AMD and 60 normal control subjects. Peripheral blood was collected from each participant for DNA extraction. Following amplification by polymerase chain reaction, the DNA samples were sequenced, and polymorphism of the $\mathrm{CFH}$ gene was examined. Data were analyzed with the chi-square test, with $\mathrm{P}<0.05$ signifying statistical significance. The frequency of the $\mathrm{C}$ allele was significantly higher in the wet than in the dry AMD group (P $=0.044)$. In addition, the TC and CC genotypes were markedly more common in the former than in the control group $(\mathrm{P}=0.013)$, and there
\end{abstract}


was a significant difference in the distribution of the $\mathrm{T}$ and $\mathrm{C}$ alleles between wet AMD patients and control subjects $(\mathrm{P}<0.05)$. Based on this, we conclude that liver-kidney yin-deficiency AMD is associated with the $\mathrm{C}$ allele and $\mathrm{TC}$ and $\mathrm{CC}$ genotypes of the $\mathrm{CFH} \mathrm{Y} 402 \mathrm{H}$ polymorphism. Among patients with this condition, $C F H$ genotypes were normally distributed. The principal $\mathrm{CFH}$ genotypes that induce liver-kidney yin-deficiency AMD are the mutant homozygote $\mathrm{CC}$ and heterozygote TC forms. Moreover, $\mathrm{C}$ allele carriers are at higher risk of developing this disease.

Key words: Liver-kidney yin deficiency type; Y402H polymorphism; Age-related macular degeneration; $\mathrm{CFH}$ gene

\section{INTRODUCTION}

Age-related macular degeneration (AMD) is also known as senile macular degeneration. In recent years, as the population of China has aged, AMD-associated morbidity has been rising consistently, gradually making AMD the eye disease of most concern (Apte, 2008; Schramm et al., 2014). Currently, treatment of wet AMD principally relies on glucocorticoids, photodynamic therapy, laser photocoagulation, intravitreal injection of antivascular endothelial growth factor drugs, and macular surgery (Delcourt et al., 2001; Mulder et al., 2010). Recently, research concerning AMD pathogenesis has developed rapidly, mainly owing to genomic approaches, providing new ideas and methods for inserting foreign genes into target cells (Michels and Rosenfeld, 2005).

CFH polymorphism is closely related to the development of AMD. As our knowledge of genetics and inflammatory immunity has progressed, many genes associated with AMD are gradually being discovered, such as $\mathrm{CFH}$, complement component 2, complement factor $\mathrm{B}$, apolipoprotein $\mathrm{E}$, hemicentin 1, and low-density lipoprotein receptor-related protein 6 (Dikmetas et al., 2013). The influence of $C F H$ in this regard has been widely recognized in the literature, with the $\mathrm{CFH}$ polymorphism being identified as a key pathogenic factor in AMD, and used successfully in genetic studies to generate models of this disease (Imai et al., 2010; Abbas and Azzazy, 2013). Variation in the $C F H$ gene mainly manifests as the polymorphism Y402H (T1277C), in which a T-to-C substitution at position 1277 in exon 9 leads to a change at residue 402 in the translated sequence, from tyrosine to histidine $(\mathrm{Y} 402 \mathrm{H})$. The $\mathrm{C}$ allele, which is associated with high risk of AMD, is present in 50.0 to $57.3 \%$ of cases (Trouw et al., 2011; Zhong et al., 2011).

External factors can induce such mutations, thus causing $C F H$ gene polymorphism, and consequently, decreased expression of the encoded protein. Therefore, variation in the $C F H$ gene, consisting of polymorphism, is a key pathogenic factor in AMD. Using molecular biological methods, the present study revealed that $\mathrm{CFH}$ genotypes were distributed regularly among patients with liver-kidney yin-deficiency AMD, the mutant homozygote $\mathrm{CC}$ and heterozygote $\mathrm{TC}$ genotypes predominated in this group, $\mathrm{CFH}$ variation characterized by polymorphism was closely associated with AMD, and the $\mathrm{C}$ allele was a pathogenic factor conferring high risk of this disease. In brief, this study provides guidance for AMD research and treatment in the context of traditional Chinese medicine.

Genetics and Molecular Research 15 (3): gmr.15038457 


\section{MATERIAL AND METHODS}

\section{General materials}

We selected 60 liver-kidney yin-deficiency AMD patients (the test group, comprising 20 men and 40 women) having been treated in the ophthalmology and in-patient departments of the First Affiliated Hospital of Zhengzhou University from January 2013 to June 2015. Using routine examination procedures for this disease and tests of general health, these patients were found to conform to the inclusion criteria. In addition, we enrolled 60 healthy people (24 men and 36 women) for the control group. We then analyzed the characteristics of $\mathrm{CFH}$ gene variation with molecular biological techniques. Before participation, the patients and their families were informed of the research process and potential risks in detail, and their rights of informed consent were fully respected. In addition, voluntarily signed written informed consent was obtained from the patients' families and included in their medical records. This study was assessed by the medical research Ethics Committee of the First Affiliated Hospital of Zhengzhou University, and was in accordance with international and national ethics requirements for biomedical research. Therefore, the performance of this study was approved.

\section{Diagnostic criteria}

\section{AMD diagnostic criteria}

The diagnostic criteria for dry (atrophic) AMD were as follows: patients were over 55 years old; eyesight had weakened gradually; the fundus showed early macular depigmentation; the central light reflex was not clear; in the early phase, quasi-circular yellowish-white drusen were observed; in the late phase of lesions, pigment disorder, depigmentation, or geographic atrophy were seen; fundus fluorescein angiography (FFA) showed no fluorescein leakage or weak fluorescence in the macular area.

The diagnostic criteria for wet (exudative) AMD were as follows: patients were over 55 years old; eyesight had weakened rapidly; in the early phase, the fundus exhibited a grayish-yellow lesion in the macular area; the light reflex was not clear or was lost in the macula fovea centralis; drusen were present; edema was observed in the area of the lesion; during the intermediate phase, serous or hemorrhagic retinal pigment epithelial detachment in the macular area was seen; in more serious cases, subretinal, intraretinal, or vitreous hemorrhage was noted; scars formed in the late phase of lesions; FFA showed choroidal neovascularization in the macular area, fluorescent leakage, and blocked fluorescence caused by hemorrhage.

\section{Control group criteria}

Control subjects were at least 55 years old and were free of AMD and other eye diseases. In this study, we examined three recognized AMD risk factors, including smoking, body mass index (BMI), and blood pressure. The following were considered to increase risk: smoking at least one cigarette per day for more than 2 years; being overweight (BMI $\geq 23.0$ $\left.\mathrm{kg} / \mathrm{m}^{2}\right)$; and having high blood pressure, defined as systolic pressure $\geq 160 \mathrm{mmHg}$, diastolic pressure $\geq 95 \mathrm{mmHg}$, and a history of high blood pressure.

Genetics and Molecular Research 15 (3): gmr.15038457 


\section{Liver-kidney yin deficiency diagnostic criteria}

According to the state standard, the diagnostic criteria for liver-kidney yin deficiency included thirst, dry throat, dysphoria in the chest, palms, and soles, dizziness, tinnitus, lumbar debility, insomnia, drowsiness, a red tongue with little coating, and a weak pulse.

\section{AMD inclusion criteria}

In the test group, patients met the diagnostic criteria of AMD and liver-kidney yin deficiency and gave their signed informed consent. Control subjects had no eye diseases. In both groups, ages ranged from 55 to 90 years.

\section{Exclusion criteria}

Reasons for exclusion included: pregnancy, lactation, abnormal liver function, a history of allergy, serious primary diseases of the heart, blood vessels, liver, kidney, or hematopoietic system, mental illness, poor compliance, inconvenience of regular examination or treatment, and refusal to sign informed consent.

\section{Clinical examination indexes}

Assessments of general health, including blood, urine, and stool examination, liver function testing, and an electrocardiogram were carried out. Routine examination for AMD was performed before inclusion of patients, using the following indexes and instruments: eyesight test, slit lamp, Amsler chart, ophthalmoscope, perimetry, FFA, and optical tomography.

\section{CFH genotyping}

Venous blood sampling of AMD patients and control subjects was performed to establish the distribution of the TT, TC, and CC genotypes and $\mathrm{C}$ allele of the $C F H$ polymorphism.

\section{Procedure}

Firstly, genomic DNA was extracted. Fasting peripheral venous blood $(2 \mathrm{~mL})$ was collected using $2 \%$ ethylenediaminetetraacetic acid as an anticoagulant. Total genomic DNA was then isolated and preserved at $-80^{\circ} \mathrm{C}$.

Secondly, polymerase chain reaction (PCR) amplification in combination with restriction fragment length polymorphism (RFLP) was used for analysis of $\mathrm{CFH}$ sequence variations. The following primers targeting the $C F H$ Y402H (rs1061170) region were synthesized: forward $(10 \mu \mathrm{M}), 5$ '-TCA TTG TTA TGG TCC TTA GGA AA-3'; and reverse $(10 \mu \mathrm{M}), 5$ '-TTA GAAAGA CAT GAA CAT GCT AGG-3'. The 10- $\mu$ L PCR system comprised $1.0 \mu \mathrm{L} 10 \mathrm{X}$ Taq buffer, $0.5 \mu \mathrm{L}$ deoxynucleotides $(2.5 \mathrm{mM}), 0.1 \mu \mathrm{L}$ each rs 1061170 primer $(50$ $\mu \mathrm{M}), 0.06 \mu \mathrm{L}$ DreamTaq (5 U/ $\mu \mathrm{L}$; Thermo Scientific, Waltham, MA, USA), $7.94 \mu \mathrm{L}$ distilled $\mathrm{H}_{2} \mathrm{O}$, and $0.3 \mu \mathrm{L}$ template DNA. Amplification conditions consisted of $95^{\circ} \mathrm{C}$ pre-denaturation for $5 \mathrm{~min}$, and 40 cycles of $95^{\circ} \mathrm{C}$ denaturation for $30 \mathrm{~s}, 60^{\circ} \mathrm{C}$ annealing for $45 \mathrm{~s}$, and $72^{\circ} \mathrm{C}$

Genetics and Molecular Research 15 (3): gmr.15038457 
extension for $60 \mathrm{~s}$. Alleles were detected using the restriction enzyme Hin 1II. Enzyme digestion products were separated into different bands by $2 \%$ agarose gel electrophoresis alongside a DNA size marker, and following ethidium bromide staining, the results were observed under an ultraviolet lamp.

Thirdly, the fragments resulting from restriction enzyme digestion of the PCR product were analyzed. The total length of the amplified $C F H \mathrm{Y} 402 \mathrm{H}$ (rs1061170)-containing sequence was $241 \mathrm{bp}$. After Hin 1II digestion, the wild-type (TT), heterozygous (TC), and homozygous mutant (CC) fragments were identified. To verify these PCR-RFLP results, PCR products for each genotype were sequenced.

\section{Statistical methods}

Using the SPSS 19.0 statistical software (IBM Corp., Armonk, NY, USA), a database was created, into which results were logged. After checks and modifications, the database was converted to generate SPSS 19.0 data files. The correlation between liverkidney yin-deficiency AMD and the TC and CC genotypes of $C F H$ Y402H was analyzed with the chi-square test. This showed that the $\mathrm{C}$ allele was associated with a high risk of this disease.

\section{RESULTS}

\section{General characteristics of the study population}

In strict accordance with the inclusion and exclusion criteria, we selected 60 liverkidney yin-deficiency AMD patients undergoing treatment in the ophthalmology and inpatient departments of the First Affiliated Hospital of Zhengzhou University from January 2013 to June 2015 . Their average age was $66.7 \pm 6.9$ years (Table 1 ). Sixty healthy people were selected for the control group, with an average age of $66.2 \pm 6.3$ years. Differences in age between the test and control groups were not significant, with the $t$-test returning a $P$ value of 0.521 . There were 20 male and 40 female test subjects and 24 male and 36 female control participants. Using the chi-square test, no statistically significant difference in gender was detected between the two groups $(\mathrm{P}=0.62)$. Neither smoking history (Table 2 ) nor BMI (Table 3$)$ significantly differed between the groups $(\mathrm{P}>0.05)$. However, high blood pressure (Table 4) was significantly more common among AMD patients than control subjects $(\mathrm{P}<0.05)$.

\section{Table 1. Age and gender distribution within the study population.}

\begin{tabular}{l|c|c|c|c|c|c}
\hline \multirow{2}{*}{ Age (years) } & \multicolumn{3}{|c|}{ Test group } & \multicolumn{3}{c}{ Control group } \\
\cline { 2 - 7 } & Male & Female & Total & Male & Female & Total \\
\hline $55-65$ & 2 & 2 & 4 & 3 & 12 & 21 \\
\hline $66-75$ & 7 & 15 & 22 & 9 & 14 & 21 \\
\hline $76-85$ & 8 & 17 & 25 & 5 & 8 & 13 \\
\hline$>85$ & 3 & 6 & 60 & 24 & 36 & 6 \\
\hline Total & 20 & 40 & 9 & 5 & \\
\hline
\end{tabular}

For age, chi-square $=2.268$ and $\mathrm{P}=0.521$, indicating no statistically significant difference. For gender, chi-square $=0.248$ and $\mathrm{P}=0.619$, indicating no statistically significant difference. 
Table 2. Statistics regarding smoking status of the test and control subjects.

\begin{tabular}{l|c|c|c|c|c}
\hline & Test group & Control group & Odds ratio (95\%CI) & Chi-square & P \\
\hline Smokers & $28(46.67 \%)$ & $33(55.00 \%)$ & $1.128(0.912-1.396)$ & 1.205 & 0.273 \\
\hline Non-smokers & $32(53.33 \%)$ & $27(45.00 \%)$ & $0.889(0.711-1.098)$ & & \\
\hline
\end{tabular}

$\mathrm{CI}=$ confidence interval.

Table 3. Statistics concerning body mass index in the test and control groups.

\begin{tabular}{l|c|c|c|c|c}
\hline & Test group & Control group & Odds ratio (95\%CI) & Chi-square & P \\
\hline Higher than normal & $21(35.00 \%)$ & $19(31.67 \%)$ & $1.097(0.846-1.429)$ & 0.496 & 0.479 \\
\hline Normal & $39(65.00 \%)$ & $41(68.33 \%)$ & $0.937(0.785-1.121)$ & & \\
\hline
\end{tabular}

$\mathrm{CI}=$ confidence interval.

Table 4. Statistics concerning blood pressure of test and control subjects.

\begin{tabular}{l|c|c|c|c|c}
\hline & Test group & Control group & Odds ratio (95\%CI) & Chi-square & P \\
\hline Normal & $38(63.33 \%)$ & $44(73.33 \%)$ & $1.176(1.008-1.368)$ & 4.296 & 0.041 \\
\hline High blood pressure & $22(36.67)$ & $16(26.67 \%)$ & $0.724(0.531-0.992)$ & & \\
\hline
\end{tabular}

$\mathrm{CI}=$ confidence interval.

\section{PCR amplification}

A 241-bp DNA band was amplified for each AMD patient and control subject (Figure 1). By comparison with a DNA size marker, the PCR product length was in accordance with expectations from the primer design.



Figure 1. Agarose gel electrophoresis of the target gene polymerase chain reaction product. Lane $M$ is a DL2000 marker; lanes 1 to 7 contain amplified genomic DNA from collected samples.

The PCR product was digested with a restriction enzyme (Fujian Huacan Pharmaceutical Co., Ltd., Sanming City, Fujian Province, China), and $5 \mu \mathrm{L}$ of this reaction mixture was subjected to $2 \%$ agarose gel electrophoresis, by which the genotype of each study subject could be accurately identified (Figure 2). Approximately $20 \%$ of the samples were 
selected randomly for genotype verification by sequencing. The results were consistent with those obtained by restriction enzyme digestion (100\% accuracy).

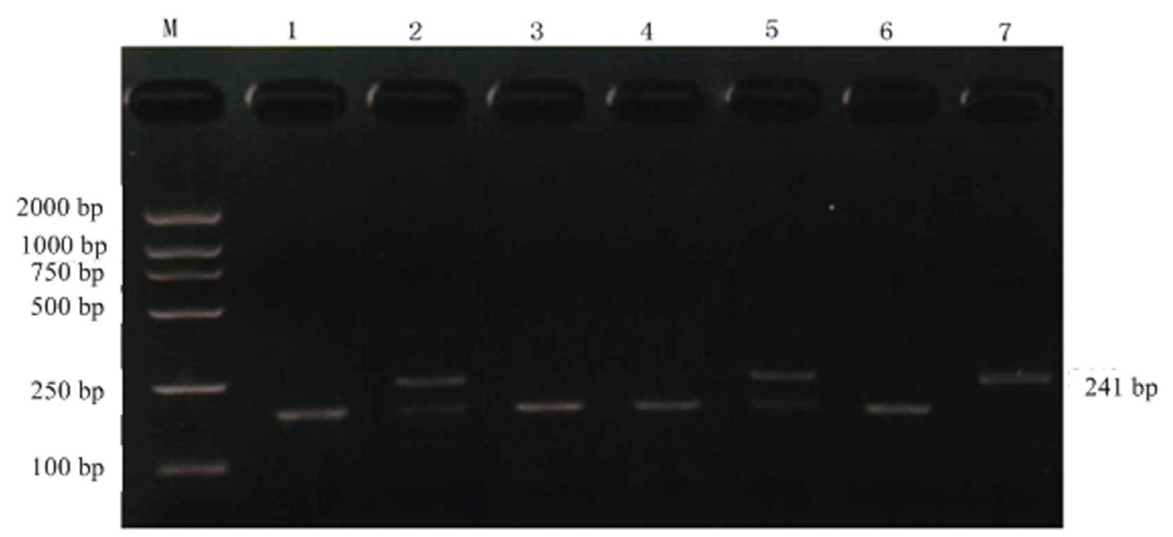

Figure 2. Restriction enzyme digestion typing of the $\mathrm{Y} 402 \mathrm{H} \mathrm{CFH} \mathrm{gene} \mathrm{polymorphism.} \mathrm{Lane} 1$ is a DL2000 marker; lanes 1, 3, 4, and 6 show the TT genotype; lanes 2 and 5, the TC genotype; and lane 7, the CC genotype.

\section{DNA sequencing results}

PCR product sequencing successfully identified the T-to-C mutation at position 1277 in exon 9 of the $C F H$ gene, leading codon 402 to encode histidine rather than tyrosine $(\mathrm{Y} 402 \mathrm{H})$. A T residue at this position was also detected in some samples, representing the wild-type sequence.

\section{Correlation analysis of the $\mathrm{Y} 402 \mathrm{H} \mathrm{CFH}$ polymorphism and AMD}

The distribution of $\mathrm{Y} 402 \mathrm{H}$ alleles and genotypes in the control group was in accordance with the Hardy-Weinberg equilibrium. The allele and genotype frequencies of this polymorphism did not significantly differ between the overall test and control groups ( $\mathrm{P}$ $=0.093$ and 0.098 , respectively), nor between the dry AMD and control groups $(\mathrm{P}=0.724$ and 0.711 , respectively). However, the frequency of the $\mathrm{C}$ allele $(\mathrm{P}=0.012)$ and TC and CC genotypes $(\mathrm{P}=0.013)$ was markedly higher among wet $\mathrm{AMD}$ patients than control subjects. In addition, we compared the two AMD groups, finding that genotype frequencies were not significantly different among patients with the dry and wet forms of this disease $(\mathrm{P}=0.052)$, although the $\mathrm{C}$ allele was significantly more common in latter than the former $(\mathrm{P}=0.044)$. Statistical data are shown in Tables 5 and 6.

Table 5. Statistical analysis of allele frequencies in age-related macular degeneration (AMD) and control groups.

\begin{tabular}{|c|c|c|c|c|c|c|c|}
\hline \multirow[t]{2}{*}{ Group } & \multicolumn{2}{|c|}{ Allele } & \multirow[t]{2}{*}{ Chi-square } & \multirow[t]{2}{*}{$P$} & \multirow[t]{2}{*}{ OR $(95 \% \mathrm{CI})$} & \multirow[t]{2}{*}{ Chi-square } & \multirow[t]{2}{*}{$P$} \\
\hline & $\mathrm{C}(\%)$ & $\mathrm{T}(\%)$ & & & & & \\
\hline Control & $46(76.70 \%)$ & $14(23.30 \%)$ & - & - & - & - & - \\
\hline Dry AMD & $3(5.00 \%)$ & $12(20.00 \%)$ & 0.126 & 0.724 & $1.133(0.574-2.221)$ & \multirow[t]{3}{*}{3.984} & \multirow[t]{3}{*}{0.044} \\
\hline Wet AMD & $9(15.00 \%)$ & $36(60.00 \%)$ & 6.577 & 0.012 & $2.215(1.193-4.114)$ & & \\
\hline Overall AMD & $12(20.00 \%)$ & $48(80.00 \%)$ & 2.832 & 0.093 & $1.603(0.923-2.781)$ & & \\
\hline
\end{tabular}

$\mathrm{OR}=$ odds ratio, $\mathrm{CI}=$ confidence interval. 
Table 6. Statistical analysis of genotype frequencies in age-related macular degeneration (AMD) and control groups.

\begin{tabular}{|c|c|c|c|c|c|c|c|c|c|}
\hline \multirow[t]{2}{*}{ Group } & \multicolumn{3}{|c|}{ Genotype } & \multirow[t]{2}{*}{ HWE } & \multirow[t]{2}{*}{ Chi-square } & \multirow[t]{2}{*}{$\mathrm{P}$} & \multirow[t]{2}{*}{ OR $(95 \% \mathrm{CI})$} & \multirow[t]{2}{*}{ Chi-square } & \multirow[t]{2}{*}{$P$} \\
\hline & TT (\%) & TC $(\%)$ & $\mathrm{CC}(\%)$ & & & & & & \\
\hline Control & $38(63.33)$ & $16(26.67)$ & $6(10.00)$ & 0.34 & - & - & - & - & - \\
\hline Dry AMD & $4(6.67)$ & $8(13.33)$ & $36(60.00)$ & 0.40 & 0.137 & $0.711^{*}$ & $1.142(0.564-2.313)$ & 3.798 & 0.052 \\
\hline Wet AMD & $2(3.33)$ & $4(6.67)$ & $6(10.00)$ & 0.45 & 6.318 & $0.013^{*}$ & $2.315(0.790-4.504)$ & & \\
\hline Overall AMD & $6(10.00)$ & $12(20.00)$ & $42(70.00)$ & 0.36 & 2.751 & $0.098^{*}$ & $1.631(0.911-2.912)$ & & \\
\hline
\end{tabular}

*TC and $\mathrm{CC}$ genotype frequencies were merged before comparison when the latter was low. $\mathrm{OR}=$ odds ratio, $\mathrm{CI}$ $=$ confidence interval.

\section{DISCUSSION}

In this study, we identified a significant correlation between AMD pathogenesis and high blood pressure, but not smoking or BMI. Moreover, the Y402H polymorphism of the $\mathrm{CFH}$ gene was significantly associated with wet, but not dry, AMD. Taking into account current academic research, the etiology and pathogenesis of this disease remain unclear, yet an in-depth understanding of AMD risk factors is an important prerequisite for its prevention and treatment. Age is well recognized as a major contributor to AMD susceptibility, as is smoking (Clemons et al., 2005). Although the literature is not always consistent on this subject, it has been speculated that smoking may triple the risk of developing AMD (Buch, 2005) by affecting the retinal pigment epithelium, thus increasing oxidative stress and compromising microcirculation in the choroid blood vessels. In this study, smoking history was not significantly related to AMD pathogenesis, perhaps owing to the limited sample size. Due to the limitation of experimental instruments, we did not statistically assess other risk factors, such as oxidant intake and sun exposure. In addition to these environmental influences, systemic diseases or changes in body indexes (such as elevated BMI and C-reactive protein levels) may also be risk factors for eye diseases (Kaushik et al., 2008; van de Ven et al., 2012).

The role of genetic factors in the pathogenesis of AMD is a current focus of research. A related investigation found that the $C F H \mathrm{Y} 402 \mathrm{H}$ polymorphism is significantly linked with susceptibility to wet AMD (Soubrane et al., 2003). In recent years, a number of research groups in North America have demonstrated that AMD risk is higher for carriers of this variant, and this has been confirmed by researchers in Finland, Italy, and France (Axer-Siegel et al., 2004; Shyong et al., 2005). In a Japanese study (Tanaka et al., 2011), the frequency of $\mathrm{Y} 402 \mathrm{H}$ was found to be $4 \%$ in AMD and control groups, and two CFH haplotypes (IVS6 and Q672Q) were identified as AMD risk factors. In addition, a further haplotype (I62V) was reported to exert a favorable effect in AMD patients. Thus, we can conclude that the $C F H$ polymorphism is related to this condition's pathogenesis, yet there have been no reports of this in China. In the present study, among the 60 AMD patients, $6(10 \%), 12(20 \%)$, and $42(70 \%)$ carried the TT, TC, and CC genotypes, respectively. Of the 60 healthy controls, these figures were $38(63.3 \%), 16(26.7 \%)$, and $6(10 \%)$, respectively. Comparing the AMD and control groups, statistical analysis revealed a significant difference in $C F H$ polymorphism genotype frequencies $(\mathrm{P}<0.05)$. The $\mathrm{C}$ and $\mathrm{T}$ alleles were present in 80 and $20 \%$ of the AMD patients and 76.7 and $23.3 \%$ of the control subjects, respectively. Accordingly, the distribution of these alleles significantly differed between wet AMD and control groups $(\mathrm{P}<0.05)$. Therefore, liver-kidney yin-deficiency AMD is associated with the $\mathrm{C}$ allele and TC and $\mathrm{CC}$ genotypes of $\mathrm{CFH}$ Y $402 \mathrm{H}$. Among patients with this disease, $\mathrm{CFH}$ genotypes were normally distributed,

Genetics and Molecular Research 15 (3): gmr.15038457 
and the mutant homozygote $\mathrm{CC}$ and heterozygote $\mathrm{TC}$ forms predominated. Variation in the $\mathrm{CFH}$ gene is obviously connected with AMD, the T-to-C base change being a key variant in this relationship (Hooper et al., 2008; Biswas et al., 2011). Ages of patients with liver-kidney yin-deficiency AMD and control subjects were normally distributed, and according to the $t$-test, did not significantly differ $(\mathrm{P}>0.05)$. In addition, based on the chi-square test, these groups showed no difference in terms of gender $(\mathrm{P}>0.05)$.

As the main inhibitor of the complement system, the $\mathrm{CFH}$ protein plays an important role in complement activation. $\mathrm{CFH}$ can combine with $\mathrm{C} 3 \mathrm{~b}$, inhibiting the formation of alternative-pathway $\mathrm{C} 3$ convertase, regulating and controlling the extent of complement activation (Yücel et al., 2012). Environmental factors such as obesity and smoking can interact with the $\mathrm{CFH}$ gene polymorphism, leading to reduced $\mathrm{CFH}$ expression and activation of the complement system, and therefore significantly increasing the concentrations of C5b-9 (membrane attack complex) and C3b (Atmaca et al., 2011; Schmitz-Valckenberg et al., 2011; Cruz-Guilloty et al., 2014). C5b-9 is deposited on the basement membrane of retinal pigment epithelium (RPE) cells, accelerating the formation of drusen. Deposition also occurs between the RPE and Bruch's membrane, resulting in degeneration of the RPE-Bruch's membranechoriocapillaris complex, as well as atrophy of the macular area and posterior pole (Seddon et al., 2007). Furthermore, the collagen within Bruch's membrane thickens, and fracturing of its elastic fiber layer accelerates. The choriocapillaris enters the retinal neuroepithelium layer and RPE, resulting in subretinal neovascularization, aggravating AMD (Smailhodzic et al., 2012).

In this study, different $C F H$ genotypes were analyzed. The pathogenesis of liver-kidney yin-deficiency AMD was found to be associated with the T-to-C polymorphism at position 1277 of the $C F H$ gene. Among patients with this condition, $C F H$ genotypes were distributed regularly and the mutant homozygote $\mathrm{CC}$ and heterozygote $\mathrm{TC}$ genotypes predominated. The $\mathrm{C}$ allele was observed to be a pathogenic factor conferring high risk of liver-kidney yindeficiency AMD. Moreover, this disease was not determined to be significantly related to age or gender in either of the study groups.

\section{Conflicts of interest}

The authors declare no conflict of interest.

\section{ACKNOWLEDGMENTS}

Research supported by the National Science Foundation of China (\#U1304812).

\section{REFERENCES}

Abbas RO and Azzazy HM (2013). Association of single nucleotide polymorphisms in CFH, ARMS2 and HTRA1 genes with risk of age-related macular degeneration in Egyptian patients. Ophthalmic Genet. 34: 209-216. http://dx.doi.or $\mathrm{g} / 10.3109 / 13816810.2012 .762934$

Apte RS (2008). Pegaptanib sodium for the treatment of age-related macular degeneration. Expert Opin. Pharmacother. 9: 499-508. http://dx.doi.org/10.1517/14656566.9.3.499

Atmaca L, Idil A and Atmaca-Sönmez P (2011). Laser treatment in 341 patients with exudative age-related macular degeneration. Int. J. Ophthalmol. 4: 73-77.

Axer-Siegel R, Ehrlich R, Yassur Y, Rosenblatt I, et al. (2004). Photodynamic therapy for age-related macular degeneration in a clinical setting: visual results and angiographic patterns. Am. J. Ophthalmol. 137: 258-264. http:// dx.doi.org/10.1016/j.ajo.2003.08.009

Genetics and Molecular Research 15 (3): gmr.15038457 
Biswas P, Sengupta S, Choudhary R, Home S, et al. (2011). Comparative role of intravitreal ranibizumab versus bevacizumab in choroidal neovascular membrane in age-related macular degeneration. Indian J. Ophthalmol. 59: 191-196. http://dx.doi.org/10.4103/0301-4738.81023

Buch H (2005). Fourteen-year incidence of age-related maculopathy and cause-specific prevalence of visual impairment and blindness in a Caucasian population: the Copenhagen City Eye Study. Acta Ophthalmol. Scand. 83: 400-401. http://dx.doi.org/10.1111/j.1600-0420.2005.00474.x

Clemons TE, Milton RC, Klein R, Seddon JM, et al.; Age-Related Eye Disease Study Research Group (2005). Risk factors for the incidence of advanced age-related macular degeneration in the Age-Related Eye Disease Study (AREDS) AREDS report No. 19. Ophthalmology 112: 533-539. http://dx.doi.org/10.1016/j.ophtha.2004.10.047

Cruz-Guilloty F, Saeed AM, Duffort S, Cano M, et al. (2014). T cells and macrophages responding to oxidative damage cooperate in pathogenesis of a mouse model of age-related macular degeneration. PLoS One 9: e88201. http://dx.doi. org/10.1371/journal.pone.0088201

Delcourt C, Carrière I, Ponton-Sanchez A, Fourrey S, et al.; POLA Study Group (2001). Light exposure and the risk of age-related macular degeneration: the Pathologies Oculaires Liées à l'Age (POLA) study. Arch. Ophthalmol. 119: 1463-1468. http://dx.doi.org/10.1001/archopht.119.10.1463

Dikmetas O, Kadayıfcilar S and Eldem B (2013). The effect of $C F H$ polymorphisms on the response to the treatment of age-related macular degeneration (AMD) with intravitreal ranibizumab. Mol. Vis. 19: 2571-2578.

Hooper P, Jutai JW, Strong G and Russell-Minda E (2008). Age-related macular degeneration and low-vision rehabilitation: a systematic review. Can. J. Ophthalmol. 43: 180-187. http://dx.doi.org/10.3129/i08-001

Imai D, Mori K, Horie-Inoue K, Gehlbach PL, et al. (2010). CFH, VEGF, and PEDF genotypes and the response to intravitreous injection of bevacizumab for the treatment of age-related macular degeneration. J. Ocul. Biol. Dis. Infor. 3: 53-59. http://dx.doi.org/10.1007/s12177-010-9055-1

Kaushik S, Wang JJ, Flood V, Tan JS, et al. (2008). Dietary glycemic index and the risk of age-related macular degeneration. Am. J. Clin. Nutr. 88: 1104-1110.

Michels S and Rosenfeld PJ (2005). Treatment of neovascular age-related macular degeneration with Ranibizumab/ Lucentis. Klin. Monatsbl. Augenheilkd. 222: 480-484. http://dx.doi.org/10.1055/s-2005-858315

Mulder DJ, Bieze M, Graaff R, Smit AJ, et al. (2010). Skin autofluorescence is elevated in neovascular age-related macular degeneration. Br. J. Ophthalmol. 94: 622-625. http://dx.doi.org/10.1136/bjo.2009.162990

Schmitz-Valckenberg S, Brinkmann CK, Alten F, Herrmann P, et al. (2011). Semiautomated image processing method for identification and quantification of geographic atrophy in age-related macular degeneration. Invest. Ophthalmol. Vis. Sci. 52: 7640-7646. http://dx.doi.org/10.1167/iovs.11-7457

Schramm K, Mueller M, Koch FH, Singh P, et al. (2014). Effects of core vitrectomy in the treatment of age-related macular degeneration. Acta Ophthalmol. 92: 465-472. http://dx.doi.org/10.1111/aos.12326

Seddon JM, Francis PJ, George S, Schultz DW, et al. (2007). Association of CFH Y402H and LOC387715 A69S with progression of age-related macular degeneration. JAMA 297: 1793-1800. http://dx.doi.org/10.1001/jama.297.16.1793

Shyong MP, Lee FL, Chen SJ, Tung TH, et al. (2005). Photodynamic therapy for subfoveal choroidal neovascularization secondary to age-related macular degeneration. J. Chin. Med. Assoc. 68: 419-424. http://dx.doi.org/10.1016/S17264901(09)70157-1

Smailhodzic D, Muether PS, Chen J, Kwestro A, et al. (2012). Cumulative effect of risk alleles in CFH, ARMS2, and $V E G F A$ on the response to ranibizumab treatment in age-related macular degeneration. Ophthalmology 119: 23042311. http://dx.doi.org/10.1016/j.ophtha.2012.05.040

Soubrane G, Souied E, Haddad W, Razavi S, et al. (2003). Alternative therapies for choroidal neovessels resulting from age-related macular degeneration. J. Fr. Ophtalmol. 26: 876-878.

Tanaka K, Nakayama T, Yuzawa M, Wang Z, et al. (2011). Analysis of candidate genes for age-related macular degeneration subtypes in the Japanese population. Mol. Vis. 17: 2751-2758.

Trouw LA, Böhringer S, Daha NA, Stahl EA, et al. (2011). The major risk alleles of age-related macular degeneration (AMD) in CFH do not play a major role in rheumatoid arthritis (RA). Clin. Exp. Immunol. 166: 333-337. http:// dx.doi.org/10.1111/j.1365-2249.2011.04482.x

van de Ven JP, Smailhodzic D, Boon CJ, Fauser S, et al. (2012). Association analysis of genetic and environmental risk factors in the cuticular drusen subtype of age-related macular degeneration. Mol. Vis. 18: 2271-2278.

Yücel D, Yılmaz M, Durukan AH and Özgül RK (2012). Association of CFH Y402H polymorphism with both forms of advanced age-related macular degeneration in Turkish patients. Ophthalmic Genet. 33: 144-149. http://dx.doi.org/1 $\underline{0.3109 / 13816810.2012 .660225}$

Zhong L, Yao J, Gao F, Zhou X, et al. (2011). Research on the correlation between TCM syndrome patterns of age-related macular degeneration and $C F H$ gene $\mathrm{Y} 402 \mathrm{H}$ and $C F B$ gene $\mathrm{R} 32 \mathrm{Q}$ polymorphisms. J. Nanjing Univ. Tradit. Chin. Med. 27: 516-518.

Genetics and Molecular Research 15 (3): gmr.15038457 